IZA DP No. 5313

Analysis of Labor Tax Progression under Heterogeneous Domestic Labor Markets and Flexible Outsourcing

Erkki Koskela

November 2010 


\title{
Analysis of Labor Tax Progression under Heterogeneous Domestic Labor Markets and Flexible Outsourcing
}

\author{
Erkki Koskela \\ University of Helsinki \\ and IZA
}

\author{
Discussion Paper No. 5313 \\ November 2010
}

\author{
IZA \\ P.O. Box 7240 \\ 53072 Bonn \\ Germany \\ Phone: +49-228-3894-0 \\ Fax: +49-228-3894-180 \\ E-mail: iza@iza.org
}

\begin{abstract}
Any opinions expressed here are those of the author(s) and not those of IZA. Research published in this series may include views on policy, but the institute itself takes no institutional policy positions.

The Institute for the Study of Labor (IZA) in Bonn is a local and virtual international research center and a place of communication between science, politics and business. IZA is an independent nonprofit organization supported by Deutsche Post Foundation. The center is associated with the University of Bonn and offers a stimulating research environment through its international network, workshops and conferences, data service, project support, research visits and doctoral program. IZA engages in (i) original and internationally competitive research in all fields of labor economics, (ii) development of policy concepts, and (iii) dissemination of research results and concepts to the interested public.
\end{abstract}

IZA Discussion Papers often represent preliminary work and are circulated to encourage discussion. Citation of such a paper should account for its provisional character. A revised version may be available directly from the author. 
IZA Discussion Paper No. 5313

November 2010

\section{ABSTRACT}

\section{Analysis of Labor Tax Progression under Heterogeneous Domestic Labor Markets and Flexible Outsourcing*}

What are the impacts of labor tax reform on wage setting and employment to keep the relative tax burden per low-skilled and high-skilled workers constant in the case of heterogeneous domestic labor markets, i.e. imperfect competition in low-skilled labor and perfect competition in high-skilled labor in the presence of outsourcing? A higher degree of tax progression by raising the wage tax and the tax exemption for the low-skilled workers will decrease the wage rate and increase labor demand of low-skilled workers, whereas it will decrease (increase) employment of high-skilled workers in CES utility function when the elasticity of substitution between consumption and leisure is higher (lower) than one. A higher degree of wage tax progression for the high-skilled worker will have no effect on the highskilled wage in the presence of CES utility function.

JEL Classification: E24, H22, J21, J31, J51

Keywords: heterogeneous domestic labor markets, wage bargaining, impacts of labor taxation, outsourcing

Corresponding author:

Erkki Koskela

Department of Economics

University of Helsinki

P.O. Box 17 (Arkadiankatu 7)

00014 Helsinki

Finland

E-mail: erkki.koskela@helsinki.fi

\footnotetext{
* Koskela thanks the Academy of Finland (grant No. 1217622) for financial support.
} 


\section{Introduction}

European Welfare States are characterized by dual labor markets. Unskilled workers are typically unionized, while skilled workers often negotiate on their wages individually, and, thus, face more competitive wage formation. Historically, labor unions have been able to push for relatively high wages of unskilled workers, at the cost of a higher unemployment in Continental Europe than in the United States.

During the late $20^{\text {th }}$ century and after that globalization has put the European welfare model under increasing pressure. Wage differences across countries constitute a central explanation for the increasing dominant business practice of international outsourcing across a wide range of industries (see e.g. Sinn (2007) for an overview and Stefanova (2006) concerning the East-West dichotomy of outsourcing).

Outsourcing can take two alternative forms. Firms may write long-term contracts that fix the amount of outsourcing before the trade union sets the wage, i.e. strategic outsourcing, or alternatively firms may be flexible enough to decide upon the amount of outsourcing activity simultaneously with domestic labor demand after the domestic wage is set by the trade union.

While there is a large literature on international outsourcing, only a few contributions have studied the various effects of wage taxation in its presence. Koskela and Schöb (2010) analyze in the case of monopoly trade union the impacts of labor tax policy reforms in the presence of both strategic and flexible outsourcing when domestic labor is homogeneous. This paper opens a new research theme by analyzing the effects of wage taxation with flexible international outsourcing when the domestic labor market is heterogeneous so that labor markets are imperfectly competitive in the case of low-skilled workers when monopoly labor union decides the wage rate of low-skilled workers, and perfectly competitive in the case of highskilled workers so that the high-skilled wage adjust to equalize labor demand and labor supply by also assuming CES-utility function which depends on the elasticity of substitution between consumption and leisure for high-skilled workers. I assume 
for simplicity that there is the representative firm to allow for different labor market situation. ${ }^{1}$

I find that in the presence of flexible outsourcing both in the case of highskilled workers' CES-utility function in competitive labor market equilibrium (a) the high-skilled wage depends negatively on the low-skilled wage, whereas (b) the highskilled wage depends positively (negatively) on the wage tax when the elasticity of substitution between consumption and leisure is higher (lower) than one, whereas (c) the high-skilled wage depends negatively (positively) on the tax exemption when the elasticity of substitution between consumption and leisure is higher (lower) than one. In the case of high- skilled workers' CES-utility function in competitive labor market equilibrium higher outsourcing wage and higher outsourcing cost will increase the wage for the low-skilled labor because the wage elasticity of the low-skilled labor will decrease and these will decrease the wage for the high-skilled labor.

A higher unskilled wage tax rate will increase the wage for the low-skilled labour and decrease the wage for high-skilled labor and the higher unskilled wage tax exemption will decrease the wage for the low-skilled labor and will increase the wage for the high-skilled labor. In terms of labor tax reform (a) a higher degree of tax progression by raising the wage tax and the tax exemption for the low-skilled workers to keep the relative burden per low-skilled worker constant will decrease the wage rate and increase labor demand of low-skilled workers, whereas (b) it will decrease (increase) employment of high-skilled workers in CES utility function when the elasticity of substitution between consumption and leisure is higher (lower) than one, (c) A higher low-skilled wage tax rate will increase the wage for the low-skilled labor and decrease the wage for high-skilled labor and the higher low-skilled wage tax exemption will decrease the wage for the low-skilled labor and will increase the wage for the high-skilled labor. Similar qualitative but not quantitative effects arise also in the absence of outsourcing.

Other research topic is to focus the role of heterogeneous firms to study the interaction between wage bargaining and foreign direct investment (see e.g. Eckel and Egger (2900) about this analysis but in the absence of labor market policy reforms). 
Finally, a higher degree of wage tax progression for the high-skilled worker, keeping the relative tax burden per high-skilled worker constant, will have no effect on the high-skilled wage in the presence of CES - utility function. Because there are no effect of high-skilled wage tax progression on high-skilled and low-skilled wage in the case of different tax parameters compared with low-skilled workers, there is no employment effects in this case.

Section II presents the time sequence of the decisions regarding some policy issues associated with labor taxes, wage setting for domestic low-skilled workers, labor demand for domestic high-skilled and low-skilled workers, outsourcing and wage setting for skilled workers. It is studied the segmented domestic labor demand for heterogeneous work force and outsourcing decision and wage formation of highskilled workers due to market equilibrium under labor taxation in section III. Wage formation by the monopoly labor union for low-skilled workers under a linearly progressive wage tax levied on workers is analyzed in section IV. In section V it is studied the impacts of both low-skilled skilled wage progression and high-skilled wage progression on wage setting and employment of both types of workers. Finally, it is summarized conclusions in section VI.

\section{Basic Framework}

It is analyze a model with heterogeneous domestic workers and international outsourcing. The production combines labor services by high-skilled workers and low-skilled workers. Low-skilled labor services can be provided either by the firm's own workers, or obtained from abroad through international outsourcing. It is assumed that the firms may be flexible enough to decide upon the amount of outsourcing activity only after the wage is set by the labor union. Skaksen (2004) has analyzed the implications of outsourcing for wage setting and employment under imperfectly competitive labor markets in terms of both potential (non-realized) and realized international outsourcing. Also he analyzes flexible outsourcing, but in homogenous domestic labor markets. The time sequence for this case is described by Figure 1. 


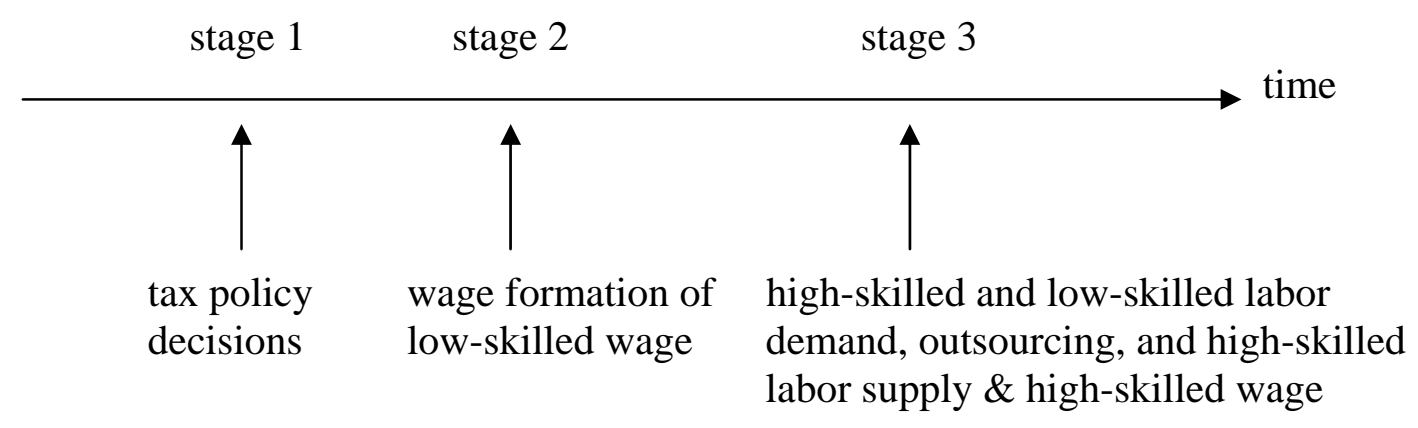

Figure 1: Time sequence of decisions

The government sets its policy at stage 1 . At stage 2 conditional on policy choices by the government, the labor union determines the wage for the low-skilled workers by taking into account how this affects the demand for labor and outsourcing by the firms. At stage 3, firms decide on domestic employment and international outsourcing. The wages of the high-skilled labor adjust to equalize labor demand and labor supply. The decisions at each stage are analyzed by using backward induction.

\section{Labor Demand, Outsourcing Decision and High-Skilled Wage Formation}

\section{III.1. High-Skilled and Low-Skilled Labor Demand and Outsourcing}

At the last stage, the firm decides on the high-skilled labor demand $H$, the low-skilled labor demand $L$ and outsourcing $M$ in order to maximize the profit function

$$
\underbrace{\operatorname{Max}}_{(H, L, M)} \pi=F(H, L, M)-w_{H} H-w_{L} L-w_{M} M-g(M)
$$

where $w_{L}$ is the wage for low-skilled labor, $w_{H}$ is the wage for high-skilled labor, and $w_{M}$ wage of outsourcing. It is assumed that while some activities are easy to outsource, some other activities are more costly to outsource. Therefore, the marginal cost of outsourcing increases in the scope of activities to outsource. To capture this effect we model the acquisition of $M$ units of the outsourced low-skilled labor input 
to require an irreversible investment $g(M)=0,5 c M^{2}$ with $g^{\prime}(M)=c M>0$ and $g^{\prime \prime}(M)=c>0$. This captures the idea that firms make irreversible investment in the establishment of networks of suppliers in the relevant low-wage countries.

I follow Koskela and Stenbacka (2010) by assuming a Cobb-Douglas-type production function with decreasing returns to scale with three labor inputs, i.e. $F(H, L, M)=\left[H^{a}(L+\gamma M)^{1-a}\right]^{\rho}$, where the parameters $\rho$ and $a$ are assumed to satisfy: $0<\rho<1$ and $\frac{1}{2}<a<1 .^{2}$ This latter specification means that the marginal productivity of the high-skilled labor is higher than that of the low-skilled labor. The parameter $\gamma>0$ captures the productivity of the outsourced low-skilled labor input relative to the domestic low-skilled labor input. The marginal products of highskilled labor, low-skilled labor and outsourcing are: $F_{H}=\rho F^{\rho-1} a H^{a-1}(L+\gamma M)^{1-a}=\rho a F / H, F_{L}=\rho(1-a) F /(L+\gamma M)$, and $F_{M}=\gamma F_{L}$. The outsourced low-skilled labor input affects the marginal products of the domestic high-skilled and low-skilled labor inputs as follows

$$
F_{H M}=\gamma F_{H L}=\frac{\rho^{2} a(1-a) \lambda}{H(L+\gamma M)} F>0 \text { and } F_{L M}=-\frac{\rho(1-a) \gamma}{(L+\gamma M)^{2}} F[1-\rho(1-a)]<0 \text {. }
$$

Thus, for this production function the domestic high-skilled labor input and the outsourced labor input are complements, whereas the low-skilled domestic labor input and the outsourced labor input are substitutes in terms of the marginal product effects of outsourcing. Also one can calculate from the production function that the domestic high-skilled and low-skilled labors are complements, i.e. $F_{H L}>0$. Given the wages, the outsourcing cost function first-order conditions characterizing the domestic high-skilled and low-skilled labor demands and outsourcing are

2 Ethier (2005) has introduced a partly related Cobb-Douglas aggregate production function, where domestic low-skilled labor and outsourcing are substitutes and domestic high-skilled labor and outsourcing are complements, to analyze the decision between international outsourcing and in-house production in the analysis of the effect of globalization on the skill premium. 


$$
\begin{gathered}
\pi_{H}=\frac{\rho a}{H} F-w_{H}=0, \\
\pi_{L}=\frac{\rho(1-a)}{(L+\gamma M)} F-w_{L}=0, \\
\pi_{M}=\frac{\rho(1-a) \gamma}{(L+\gamma M)} F-w_{M}-c M=0 .
\end{gathered}
$$

These first-order conditions (2a) and (2b) imply the following relationship between the high-skilled labor $(H)$ and the low-skilled labor inclusive of outsourcing $(L+\gamma M)$

$$
H=\frac{w_{L}}{w_{H}} \frac{a}{1-a}(L+\gamma M) .
$$

Using (2b) and (2c) we have

$$
M^{*}=\frac{\left(\gamma w_{L}-w_{M}\right)}{C}
$$

where $M_{w_{L}}^{*}, M_{\gamma}^{*}>0$, and $M_{c}^{*}, M_{w_{M}}^{*}<0$. According to (4) the higher low-skilled domestic wage rate, and the higher productivity of outsourced labor input will increase outsourcing, while the higher outsourcing wage and the higher outsource cost will decrease flexible outsourcing. In the case of production function $F(H, L, M)=\left[H^{a}(L+\gamma M)^{1-a}\right]^{\rho}$ outsourcing elasticities have the following findings: $\quad \frac{M_{w_{l}}^{*} w_{L}}{M^{*}}=\frac{M_{\gamma_{l}}^{*} \gamma_{L}}{M^{*}}=\eta_{M}^{f}=\frac{\gamma w_{L}}{\left(\gamma w_{L}-w_{M}\right)}=\frac{\gamma w_{L}}{c M^{*}}>1, \quad-\frac{M_{c}^{*} c}{M^{*}}=1 \quad$ and $-\frac{M_{w_{M}}^{*} w_{M}}{M^{*}}=\eta_{\hat{M}}^{f}=\frac{w_{M}}{\left(w_{L}-w_{M}\right)}=\frac{w_{M}}{c M^{*}}>1$. The elasticities with respect to low-skilled wage, productivity of outsourced labor input, and outsourcing wage in the presence of outsourcing are higher than one. Higher low-skilled wage will decrease these elasticities, i.e. $\frac{\partial \eta_{M}^{f}}{\partial w_{L}}=-\frac{w_{M} \gamma}{\left(\gamma w_{L}-w_{M}\right)^{2}}<0$ and higher outsourcing wage will increase 
these wage elasticities, i.e. $\frac{\partial \eta_{M}^{f}}{\partial w_{M}}=\frac{w_{L} \gamma}{\left(\gamma w_{L}-w_{M}\right)^{2}}>0$. Substituting the RHS of (3) for $H \quad$ into (2b) $\quad \rho(1-a) H^{\rho a}(L+\gamma M)^{\rho(1-a)-1}=w_{L} \quad$ gives $(1-a)\left(\frac{w_{L}}{w_{H}}\right)^{\rho a}\left(\frac{a}{1-a}\right)^{\rho a}(L+\lambda M)^{\rho-1}=\rho^{-1} w_{L}$ so that the low-skilled labor demand can be expressed as

$$
L^{*}=m w_{L}^{-\varepsilon_{L}^{L}} w_{H}^{-\varepsilon_{H}^{L}}-\gamma M^{*}=m w_{L}^{-\varepsilon_{L}^{L}} w_{H}^{-\varepsilon_{H}^{L}}-\gamma\left(\frac{\gamma w_{L}-w_{M}}{c}\right)
$$

where $m=\left[\rho a^{a \rho}(1-a)^{1-a \rho}\right] \frac{1}{1-\rho}>0, \quad \varepsilon_{L}^{L}=\frac{1-\rho a}{1-\rho}>1$ and $\varepsilon_{H}^{L}=\frac{\rho a}{1-\rho}>0$. These are higher with decreasing returns to scale. According to (5), a more extensive outsourcing activity due to a lower outsourcing cost $w_{M}$ will decrease the low-skilled labor demand, which lies in conformity with empirical evidence. ${ }^{3}$ Moreover, higher outsourcing wage will increase the low-skilled labor demand, i.e. $L_{M}^{*}=\frac{\gamma}{C}>0$. In the presence of outsourcing the wage elasticities of the low-skilled labor, $-\left.\frac{L_{w_{L}}^{*} w_{L}}{L^{*}}\right|_{M>0}$ and $-\left.\frac{L_{w_{H}}^{*} w_{H}}{L^{*}}\right|_{M>0}$, can be written as follows

$$
\eta_{L}^{f}=\varepsilon_{L}^{L}\left(1+\gamma \frac{M^{*}}{L^{*}}\right)+\frac{\gamma}{L^{*}}\left(M^{*}+\frac{w_{M}}{c}\right)=\varepsilon_{L}^{L}+\frac{\gamma}{L^{*}}\left(\left(1+\varepsilon_{L}^{L}\right) M^{*}+\frac{w_{M}}{C}\right),
$$

where $M^{*}+\frac{w_{M}}{C}=\frac{\gamma w_{L}}{c}$ and

$$
\eta_{H}^{f}=\varepsilon_{H}^{L}\left(1+\gamma \frac{M^{*}}{L^{*}}\right)
$$

For instance, Görg and Hanley (2005) have used plant-level data of the Irish electronic sector to empirically conclude that international outsourcing reduces plant-level labor demand. 
The higher is outsourcing due to various parameter changes, we then have the following effects

$$
\frac{\partial \eta_{L}^{f}}{\partial M^{*}}=\left(1+\varepsilon_{L}^{L}\right) \gamma\left[\frac{L^{*}-M^{*} L_{M}^{*}}{L^{* 2}}\right]-\frac{\gamma W_{M} L_{M}^{*}}{c L^{* 2}}=\frac{\gamma}{L^{*}}\left(\left(1+\varepsilon_{L}^{L}\right)\left(1+\gamma \frac{M^{*}}{L^{*}}\right)+\frac{\gamma W_{M}}{c L^{*}}\right)>0
$$

and $\frac{\partial \eta_{H}^{f}}{\partial M^{*}}=\varepsilon_{H}^{L} \gamma\left[\frac{L^{*}-M^{*} L_{M}^{*}}{L^{* 2}}\right]=\varepsilon_{H}^{L} \frac{\gamma}{L^{*}}\left(1+\gamma \frac{M^{*}}{L^{*}}\right)>0$. These are in conformity with empirical evidence according to which higher outsourcing increases the wage elasticities of low-skilled domestic labor demand. ${ }^{4}$ Also one can show that higher outsourcing productivity will increase the wage elasticities, i.e. $\frac{\partial \eta_{L}^{f}}{\partial \gamma}>0$.

The higher outsourcing cost and outsourcing wage will decrease the own wage elasticity of low-skilled labor

$$
\frac{\partial \eta_{L}^{f}}{\partial c}=\left(1+\varepsilon_{L}^{L}\right) \gamma\left[\frac{L^{*} M_{c}^{*}-M^{*} L_{c}^{*}}{L^{* 2}}\right]-\frac{\gamma w_{M}}{c^{2}}\left[\frac{L^{*}+c L_{c}^{*}}{L^{* 2}}\right]<0,
$$

and

$$
\frac{\partial \eta_{L}^{f}}{\partial w_{M}}=\left(1+\varepsilon_{L}^{L}\right) \gamma\left[\frac{L^{*} M_{w_{M}}^{*}-M^{*} L_{w_{M}}^{*}}{L^{* 2}}\right]+\frac{\gamma}{c}\left[\frac{L^{*}-w_{M} L_{w_{M}}^{*}}{L^{* 2}}\right]<0,
$$

and it will also have the same qualitative effects on the cross wage elasticity of lowskilled labor, i.e.

$$
\begin{aligned}
& \frac{\partial \eta_{H}^{f}}{\partial c}=\varepsilon_{H}^{L} \gamma\left[\frac{L^{*} M_{c}^{*}-M^{*} L_{c}^{*}}{L^{* 2}}\right]=\frac{\varepsilon_{H}^{L} \gamma M^{*}}{c L^{*}}\left[\frac{M_{c}^{*} c}{M^{*}}-\frac{L_{c}^{*} c}{L^{*}}\right]=-\frac{\varepsilon_{H}^{L} \gamma M^{*}}{w_{M} L^{*}}\left(1+\gamma \frac{M^{*}}{L^{*}}\right)<0, \\
& \frac{\partial \eta_{H}^{f}}{\partial w_{M}}=\varepsilon_{H}^{L} \gamma\left[\frac{L^{*} M_{w_{M}}^{*}-M^{*} L_{w_{M}}^{*}}{L^{* 2}}\right]=\frac{\varepsilon_{H}^{L} \gamma M^{*}}{w_{M} L^{*}}\left[\frac{M_{w_{M}}^{*} w_{M}}{M^{*}}-\frac{L_{w_{M}}^{*} w_{M}}{L^{*}}\right]= \\
& -\frac{\varepsilon_{H}^{L} \gamma M^{*}}{w_{M} L^{*}}\left(1+\gamma \frac{M^{*}}{L^{*}}\right) \frac{w_{M}}{c M^{*}}=-\frac{\varepsilon_{H}^{L} \gamma}{c L^{*}}\left(1+\gamma \frac{M^{*}}{L^{*}}\right)<0
\end{aligned}
$$

Slaughter (2001) and Hasan et al. (2007) have shown in empirics that international trade has increased the wage elasticity of labor demand. 
Finally, substituting the RHS of equation (5) into the relationship between $H$ and $L+\gamma M$ in equation (3) by using the production function $F(H, L, M)=\left[H^{a}(L+\gamma M)^{1-a}\right]^{\rho}$ gives the following demand for the high-skilled labor

$$
\begin{gathered}
H^{*}=\frac{m a}{1-a} w_{H}^{-\varepsilon_{H}^{H}} w_{L}^{-\varepsilon_{L}^{H}}, \\
\text { where } \varepsilon_{H}^{H}=-\frac{H_{w_{H}}^{*} w_{H}}{H^{*}}=\frac{1-\rho(1-a)}{1-\rho}>1 \text {, and } \varepsilon_{L}^{H}=-\frac{H_{w_{L}}^{*} w_{L}}{H^{*}}=\frac{\rho(1-a)}{1-\rho}>0 .
\end{gathered}
$$

These elasticities are also higher with weaker decreasing returns to scale, but in this model unlike in the case with the low-skilled labor, both the own wage and cross wage labor demand elasticities are independent of outsourcing. The higher own wage, and cross wage will of course affect negatively the high-skilled labor demand.

We can now summarize these findings regarding the properties of the domestic labor demand in the presence of flexible outsourcing as follows.

Proposition 1 In the presence of flexible outsourcing

(a) the own wage elasticity and the cross wage elasticity for the lowskilled labor demand depend negatively on the outsourcing wage and outsourcing cost, whereas

(b) both the own wage and the cross wage elasticities for the high-skilled labor demand are directly independent of the outsourcing wage and outsourcing cost.

\section{III.2. Wage Formation for High-Skilled Workers}

\section{III.2.1. Optimal Labor Supply of High-Skilled Workers}

I assume for simplicity that the market equilibrium for the high-skilled wage $w_{H}$ follows from the equality of labor demand and labor supply in the case of CES utility function for high-skilled worker. First it is derived labor supply and after that 
wage formation from market equilibrium by taking the low-skilled wage $w_{L}$ as given.

It is assumed that the government can employ the proportional wage tax $t_{H}$ for skilled worker, which is levied on the wage rate $w_{H}$ minus tax exemption $e_{H}$. Thus the total tax base in this case is $\left(w_{H}-e_{H}\right) H$, where $H$ is labor supply. In the presence of positive tax exemption the marginal wage tax exceeds the average wage tax rate $t_{H}\left(1-e_{H} / w_{H}\right)$ so that the system is linearly progressive. ${ }^{5}$ The net-of-tax wage, the skilled worker receives, is $\hat{w}_{H}=\left(1-t_{H}\right) w_{H}+t_{H} e_{H}$.

Labor supply of the high-skilled worker $H$ is determined by utility maximization s.t. $\hat{w}_{H} H=C$. Using the static CES utility function in terms of consumption $C$ and leisure $1-H$ the labor supply by the high-skilled worker is determined by maximizing

$$
u(C, H)=\left[\alpha(C)^{\frac{\delta-1}{\delta}}+(1-\alpha)(1-H)^{\frac{\delta-1}{\delta}}\right]^{\frac{\delta}{\delta-1}} \text { s.t. } \hat{w}_{H} H=C
$$

where $0<\alpha<1$, and $\delta$ describes the elasticity of substitution between consumption and leisure. By using the notation $Z=\alpha\left(\hat{w}_{H} H\right)^{\frac{\delta-1}{\delta}}+(1-\alpha)(1-H)^{\frac{\delta-1}{\delta}}$ the first-order condition for labor supply can be expressed as follows

$$
u_{H}(C, H)=Z^{\frac{1}{\delta-1}}\left[\alpha\left(\hat{w}_{H} H\right)^{-\frac{1}{\delta}} \hat{w}_{H}-(1-\alpha)(1-H)^{-\frac{1}{\delta}}\right]=0
$$

so that we have the following labor supply

$$
H^{s}=\frac{(1-\alpha)^{-\delta}}{(1-\alpha)^{-\delta}+\alpha^{-\delta}\left(\hat{w}_{H}\right)^{1-\delta}}=\frac{1}{\left[1+\left(\frac{1-\alpha}{\alpha}\right)^{\delta}\left(\hat{w}_{H}\right)^{1-\delta}\right]}
$$

For a seminal paper about tax progression, see Musgrave and Thin (1948), and for another elaboration, see e.g. Lambert (2001, chapters 7-8). 
The effects of the wage $w_{H}$, wage tax $0<t_{H}<1$ and tax exemption $e_{H} \geq 0$ on the optimal labor supply are in this case the following

$$
\begin{aligned}
& \frac{\partial H^{s}}{\partial w_{H}}=-\frac{\left(\frac{1-\alpha}{\alpha}\right)^{\delta}(1-\delta)\left(\hat{w}_{H}\right)^{-\delta}\left(1-t_{H}\right)}{\left[1+\left(\frac{1-\alpha}{\alpha}\right)^{\delta}\left(\hat{w}_{H}\right)^{1-\delta}\right]^{2}}\left\{\begin{array}{l}
> \\
=
\end{array}\right\} \text { as } \quad \delta\{=\} 1, \\
& \frac{\partial H^{s}}{\partial t_{H}}=\frac{\left(\frac{1-\alpha}{\alpha}\right)^{\delta}(1-\delta)\left(\hat{w}_{H}\right)^{-\delta}\left(w_{H}-e_{H}\right)}{\left[1+\left(\frac{1-\alpha}{\alpha}\right)^{\delta}\left(\hat{w}_{H}\right)^{1-\delta}\right]^{2}}\left\{\begin{array}{l}
< \\
= \\
>
\end{array}\right\} \text { as } \delta\left\{\begin{array}{l}
> \\
= \\
<
\end{array}\right\} 1, \\
& \frac{\partial H^{s}}{\partial e_{H}}=-\frac{\left(\frac{1-\alpha}{\alpha}\right)^{\delta}(1-\delta)\left(\hat{w}_{H}\right)^{-\delta} t_{H}}{\left[1+\left(\frac{1-\alpha}{\alpha}\right)^{\delta}\left(\hat{w}_{H}\right)^{1-\delta}\right]^{2}}\{=\} 0 \quad \text { as } \quad \delta\left\{\begin{array}{l}
> \\
< \\
<
\end{array}\right\} 1
\end{aligned}
$$

Therefore higher wage rate and tax exemption will increase (decrease) labor supply of high-skilled worker if the elasticity of substitution $\delta$ between consumption $C$ and leisure $1-H$ is higher (smaller) than one, while higher wage tax will decrease (increase) labor supply of high-skilled worker if the elasticity of substitution $\delta$ between consumption $C$ and leisure $1-H$ is higher (smaller) than one. In the case of Cobb-Douglas utility function with $\delta=1$ labor supply does not depend on wage rate, $w_{H}$, wage tax $t_{H}$ and tax exemption $e$ because $\left.H^{s}\right|_{\delta=1}=\frac{1}{\left[1+\left(\frac{1-\alpha}{\alpha}\right)\right]}=\alpha$.

\section{III.2.2.Market Equilibrium and Comparative Statics for High-Skilled Wage Formation}

Unlike in the case of low-skilled workers we assume that the high-skilled wage $w_{H}$ is determined by the market equilibrium concerning the equality of the labor demand function and the labor supply function. Now equality of demand, equation (8), and supply of labor, equation (11), $H^{*}=H^{s}$ gives 


$$
\frac{m a}{1-a} w_{H}^{-\varepsilon_{H}^{H}} w_{L}^{-\varepsilon_{L}^{H}}=\frac{1}{\left[1+\left(\frac{1-\alpha}{\alpha}\right)^{\delta}\left(\hat{w}_{H}\right)^{1-\delta}\right]},
$$

which can be expressed implicitly in terms of high-skilled and low-skilled wages as

$$
w_{H}^{-\varepsilon_{H}^{H}}+\left(\frac{1-\alpha}{\alpha}\right)^{\delta} w_{H}^{-\varepsilon_{H}^{H}} \hat{w}_{H}^{1-\delta}=\frac{(1-a)}{m a} w_{L}^{\varepsilon_{L}^{H}} .
$$

Under $\delta=1$ equation (14) can be written explicitly as $w_{H}=\left[\frac{(1-a) \alpha}{m a}\right]^{-\frac{1}{\varepsilon_{H}^{H}}} w_{L}^{-\frac{\varepsilon_{L}^{H}}{\varepsilon_{H}^{H}}}$. The relationship from the implicit function (14) between the changes in the highskilled wage $w_{H}$ and the low-skilled wage $w_{L}$ is the following one $\left[-\varepsilon_{H}^{H} w_{H}^{-\varepsilon_{H}^{H}-1}+\left(\frac{1-\alpha}{\alpha}\right)^{\delta}\left(-\varepsilon_{H}^{H} w_{H}^{-\varepsilon_{H}^{H}-1} \hat{w}_{H}^{1-\delta}+(1-\delta) w_{H}^{-\varepsilon_{H}^{H}} \hat{w}_{H}^{-\delta}\left(1-t_{H}\right)\right)\right] d w_{H}=\varepsilon_{L}^{H} \frac{(1-a)}{m a} w_{L}^{\varepsilon_{L}^{H}-1} d w_{L}$

where

$$
\begin{aligned}
& {\left[-\varepsilon_{H}^{H} w_{H}^{\varepsilon_{H}^{H}-1}+\left(\frac{1-\alpha}{\alpha}\right)^{\delta}\left(-\varepsilon_{H}^{H} w_{H}^{-\varepsilon_{H}^{H}-1} \hat{w}_{H}^{1-\delta}+(1-\delta) w_{H}^{-\varepsilon_{H}^{H}} \hat{w}_{H}^{-\delta}\left(1-t_{H}\right)\right)\right]=-\varepsilon_{H}^{H} w_{H}^{-\varepsilon_{H}^{H}-1}+} \\
& \left.\left(\frac{1-\alpha}{\alpha}\right)^{\delta}\left[\left(1-t_{H}\right)\left(1-\delta-\varepsilon_{H}^{H}\right)-\varepsilon_{H}^{H} t_{H} e w_{H}^{-1}\right)\right] w_{H}^{-\varepsilon_{H}^{H}} \hat{w}_{H}^{-\delta}<0
\end{aligned}
$$

because $1-\varepsilon_{H}^{H}=-\varepsilon_{H}^{L}=-\frac{\rho a}{1-\rho}<0$ so that $1-\varepsilon_{H}^{H}-\delta<0$. This can now be expressed as

$$
\left.\frac{d w_{H}}{d w_{L}}\right|_{\delta \neq 1}=\frac{\varepsilon_{L}^{H} \frac{(1-a)}{m a} w_{L}^{\varepsilon_{L}^{H}-1}}{\left(-\varepsilon_{H}^{H} w_{H}^{-\varepsilon_{H}^{H}-1}+\left(\frac{1-\alpha}{\alpha}\right)^{\delta}\left[\left(1-t_{H}\right)\left(1-\varepsilon_{H}^{H}-\delta\right)-\varepsilon_{H}^{H} t_{H} e_{H} w_{H}^{-1}\right] w_{H}^{-\varepsilon_{H}^{H}} \hat{w}_{H}^{-\delta}\right)}<0 .
$$

In this more general CES utility function case there is a negative relationship between the high-skilled wage and the low-skilled wage, which comes via the highskilled labor demand, where the low-skilled wage have a negative effect on the highskilled labor demand due to complementary of $H$ and $L$ in terms of production. This implies that higher outsourcing concerning domestic labor input will increase the wage rate of high-skilled workers because it decreases the wage rate of low- 
skilled-workers, which lies in conformity with empirics. It has been empirically shown that higher outsourcing will decrease wage formation of low-skilled workers and increase wage formation of high-skilled workers, i.e. that wage dispersion will increase. $^{6}$

The relationship from the implicit function (14) between the changes in the high-skilled wage $w_{H}$ and tax parameters are as follows

$$
\begin{aligned}
& \left.\frac{d w_{H}}{d t_{H}}\right|_{\delta \neq 1}=\frac{(1-\delta)\left(w_{H}-e_{H}\right)\left(\frac{(1-\alpha)}{\alpha}\right)^{\delta} w_{H}^{-\varepsilon_{H}^{H}} \hat{w}_{H}^{-\delta}}{\left(-\varepsilon_{H}^{H} w_{H}^{-\varepsilon_{H}^{H}-1}+\left(\frac{1-\alpha}{\alpha}\right)^{\delta}\left[\left(1-t_{H}\right)\left(1-\varepsilon_{H}^{H}-\delta\right)-\varepsilon_{H}^{H} t_{H} e_{H} w_{H}^{-1}\right] w_{H}^{-\varepsilon_{H}^{H}} \hat{w}_{H}^{-\delta}\right)}\{=\} 0 \text { as } \\
& \delta\left\{\begin{array}{l}
> \\
=\left\{\begin{array}{l}
> \\
<
\end{array}\right)
\end{array}\right.
\end{aligned}
$$

and

$$
\begin{aligned}
& \left.\frac{d w_{H}}{d e_{H}}\right|_{\delta \neq 1}=\frac{-(1-\delta) t_{H}\left(\frac{1-\alpha}{\alpha}\right)^{\delta} w_{H}^{-\varepsilon_{H}^{H}} \hat{w}_{H}^{-\delta}}{\left(-\varepsilon_{H}^{H} w_{H}^{-\varepsilon_{H}^{H}-1}+\left(\frac{1-\alpha}{\alpha}\right)^{\alpha}\left[\left(1-t_{H}\right)\left(1-\varepsilon_{H}^{H}-\delta\right)-\varepsilon_{H}^{H} t_{H} e_{H} w_{H}^{-1}\right] w_{H}^{-\varepsilon_{H}^{H}} \hat{w}_{H}^{-\delta}\right)}\{=\{0 \text { as } \\
& \delta\left\{\begin{array}{l}
> \\
=\left\{\begin{array}{l}
< \\
<
\end{array}\right)
\end{array}\right.
\end{aligned}
$$

According to these calculations, higher wage tax and lower tax exemption will increase (decrease) the high-skilled wage if the elasticity of substitution $\delta$ between consumption $C$ and leisure $1-H$ is higher (smaller) than one, because under these conditions labor supply decreases (increases) (see equations (12b-c for details). In the case of $\delta=1$ there is no effect of tax parameters on the high-skilled workers.

We can now summarize our findings regarding the properties of the highskilled wage determination in the presence of outsourcing as follows.

See evidence from various countries which lies in conformity with this, e.g. Braun and Scheffel (2007), Feenstra and Hanson (1999), Hijzen et al (2005), Hijzen (2007), Egger and Egger (2006), Riley and Young (2007) and Geishecker and Görg (2008). 
Proposition 2 In the presence of flexible outsourcing both in the case of high -skilled workers' CES-utility function in competitive labor market equilibrium

(a) the high-skilled wage depends negatively on the low-skilled wage, whereas

(b) the high-skilled wage depends positively (negatively) on the wage tax when the elasticity of substitution between consumption and leisure is higher (lower ) than one, whereas

(c) the high-skilled wage depends negatively (positively) on the tax exemption when the elasticity of substitution between consumption and leisure is higher (lower) than one, while the high-skilled wage is independent of tax parameters when the elasticity of substitution between consumption and leisure is one.

\section{Wage Formation by Monopoly Labor Union for Low-Skilled Workers}

Now it is analyzed the wage formation of low-skilled workers so that it takes place in anticipation of optimal labor and outsourcing decisions by the firm by focusing the wage formation by the monopoly labor union (see also Cahuc and Zylberberg (2004), p. 401 - 403 concerning the monopoly union specification), which determines the wage for low-skilled workers in anticipation of optimal inhouse low-skilled labor demand in the presence of flexible outsourcing determined simultaneously and of market equilibrium for the high-skilled wage $w_{H}$.

\section{IV.1. Wage Formation by the Monopoly Labor Union}

The market equilibrium for the high-skilled wage $w_{H}$ follows from the equality of labor demand and the labor supply by focusing the case of a CES utility function, presented in Section III. The monopoly labor union determines the wage for low-skilled workers in anticipation of optimal domestic labor demands and highskilled wage and outsourcing decisions by the firm. I assume that government can 
employ a proportional tax rate $t_{L}$, which is levied on the wage rate $w_{L}$ minus a tax exemption $e_{L}$, i.e. the total tax base is $\left(w_{L}-e_{L}\right) L^{*}$. In the presence of a positive tax exemption the marginal wage tax exceeds the average wage tax rate $t_{L}\left(1-e_{L} / w_{L}\right)$ so that the system is linearly progressive and the net-of-tax wage is $\hat{w}_{L}=\left(1-t_{L}\right) w_{L}+t_{L} e_{L}$. The labour tax systems in all the OECD countries are progressive and show significant differences in the degree of tax progression. ${ }^{7}$

The objective function of the labor union is assumed to be $V=\left(\left(1-t_{L}\right) w_{L}+t_{L} e_{L}-b_{L}\right) L^{*}+b_{L} N=\left(\hat{w}_{L}-b_{L}\right) L^{*}+b_{L} N$, where $b_{L}$ is the (exogenous) outside option available to the unskilled workers and $N$ is the number of labor union members. The monopoly labor union sets wage for the unskilled workers so as to maximize the surplus according to

$$
\begin{aligned}
& \underbrace{\max }_{\left(w_{L}\right)} V=\left(\hat{w}_{L}-b_{L}\right) L^{*}+b_{L} N \\
& \text { s.t. } L^{*}=m w_{L}^{-\varepsilon_{L}^{L}} w_{H}^{-\varepsilon_{H}^{L}}-\gamma M^{*}=m w_{L}^{-\varepsilon_{L}^{L}} w_{H}^{-\varepsilon_{H}^{L}}-\gamma\left(\frac{\gamma w_{L}-w_{M}}{c}\right) \text { and } H^{*}=H^{s}
\end{aligned}
$$

where the high-skilled labor demand is $H^{*}=\frac{m a}{1-a} w_{H}^{-\varepsilon_{H}^{H}} w_{L}^{-\varepsilon_{L}^{H}}$ and the high-skilled labor supply is $H^{s}=\frac{1}{\left[1+\left(\frac{1-\alpha}{\alpha}\right)^{\delta}\left(w_{H}\right)^{1-\delta}\right]}$, so that $H^{*}=H^{s} \quad$ implies $w_{H}^{-\varepsilon_{H}^{H}}+\left(\frac{1-\alpha}{\alpha}\right)^{\delta} w_{H}^{-\varepsilon_{H}^{H}} \hat{w}_{H}^{1-\delta}=\frac{(1-a)}{m a} w_{L}^{\varepsilon_{L}^{H}}$ (see equations (8), (11) and (14)). The firstorder condition associated with (16) can be written as (see Appendix A)

$$
\begin{aligned}
& \left.V_{w_{L}}=\left(1-t_{L}\right) w_{L}\left(1-\left(\eta_{L}^{f}+\eta_{H}^{f} \frac{d w_{H}}{d w_{L}} \frac{w_{L}}{w_{H}}\right)\right)+\left(b_{L}-t_{L} e_{L}\right)\left(\eta_{L}^{f}+\eta_{H}^{f} \frac{d w_{H}}{d w_{L}} \frac{w_{L}}{w_{H}}\right)\right)=0 \\
& \text { where } \quad \text { in } \quad \text { the } \quad \text { case } \quad \varepsilon_{L}^{H} \frac{(1-a)}{m a} w_{L}^{\varepsilon_{L}^{H}} \\
& \left.\frac{d w_{H}}{d w_{L}} \frac{w_{L}}{w_{H}}\right|_{\delta \neq 1}=\frac{\text { CES-utility function }}{\left[-\varepsilon_{H}^{H} w_{H}^{-\varepsilon_{H}^{H}}+\left(\frac{1-\alpha}{\alpha}\right)^{\delta}\left[w_{H}\left(1-t_{H}\right)\left(1-\varepsilon_{H}^{H}-\delta\right)-\varepsilon_{H}^{H} t_{H} e_{H}\right] w_{H}^{-\varepsilon_{H}^{H}} \hat{w}_{H}^{-\delta}\right]}<0 .
\end{aligned}
$$

Source: OECD (2004). 
Using the equation (14) these can be re-expressed as follows

$$
\left.\frac{d w_{H}}{d w_{L}} \frac{w_{L}}{w_{H}}\right|_{\delta \neq 1}=-\frac{\varepsilon_{L}^{H}}{\varepsilon_{H}^{H}} \frac{\left[1+\left(\frac{1-\alpha}{\alpha}\right)^{\delta} \hat{w}_{H}^{1-\delta}\right]}{\left[1+\left(\frac{1-\alpha}{\alpha}\right)^{\delta} \hat{w}_{H}^{1-\delta}-\left(\frac{1-\alpha}{\alpha}\right)^{\delta} w_{H}\left(1-t_{H}\right)(1-\delta) \hat{w}_{H}^{-\delta}\right]}=-\frac{\varepsilon_{L}^{H}}{\varepsilon_{H}^{H}} \frac{T}{U}<0
$$

and

$$
\left.\frac{d w_{H}}{d w_{L}} \frac{w_{L}}{w_{H}}\right|_{\delta=1}=-\frac{\varepsilon_{L}^{H}}{\varepsilon_{H}^{H}}<0
$$

where $\quad T=1+\left(\frac{1-\alpha}{\alpha}\right)^{\delta} \hat{w}_{H}^{1-\delta}>0$ and $\quad U=1+\left(\frac{1-\alpha}{\alpha}\right)^{\delta} \hat{w}_{H}^{-\delta}\left(t_{H} e_{H}+w_{H}\left(1-t_{H}\right) \delta\right)>0$.

Using (18a-b) in equation (17) can be presented implicitly as follows in the case of CES-utility functions (see Appendix A)

$$
\left.w_{L}^{*}\right|_{\delta \neq 1}=\left(\frac{\eta_{L}^{f}+\eta_{H}^{f} \frac{d w_{H} w_{L}}{d w_{L} w_{H}}}{\eta_{L}^{f}+\eta_{H}^{f} \frac{d w_{H} w_{L}}{d w_{L} w_{H}}-1}\right) \hat{b}_{L}=\left(\frac{\eta_{L}^{f}-\eta_{H}^{f} \frac{\varepsilon_{L}^{H}}{\varepsilon_{H}^{H}} \frac{T}{U}}{\eta_{L}^{f}-\eta_{H}^{f} \frac{\varepsilon_{L}^{H}}{\varepsilon_{H}^{H}} \frac{T}{U}-1}\right) \hat{b}_{L}
$$

and

$$
\left.w_{L}^{*}\right|_{\delta=1}=\left(\frac{\eta_{L}^{f}-\eta_{H}^{f} \frac{\varepsilon_{L}^{H}}{\varepsilon_{H}^{H}}}{\eta_{L}^{f}-\eta_{H}^{f} \frac{\varepsilon_{L}^{H}}{\varepsilon_{H}^{H}}-1}\right) \hat{b}_{L}
$$

where $\hat{b}_{L}=\frac{b_{L}-t_{L} e_{L}}{1-t_{L}}$. The own wage and cross wage elasticities of low-skilled labor demand are $\left.\eta_{L}^{f}=\varepsilon_{L}^{L}\left(1+\gamma \frac{M^{*}}{L^{*}}\right)+\gamma \frac{M^{*}}{L^{*}}+\gamma \frac{w_{M}}{c L^{*}}\right) \quad$ and $\quad \eta_{H}^{f}=\varepsilon_{H}^{L}\left(1+\gamma \frac{M^{*}}{L^{*}}\right) \quad$ (see equations (6a-6b)). These low-skilled labor demand elasticities are not constant because the low-skilled labor demand, $L^{*}=m w_{L}^{-\varepsilon_{L}^{L}} w_{H}^{-\varepsilon_{H}^{L}}-\gamma M^{*}=m w_{L}^{-\varepsilon_{L}^{L}} w_{H}^{-\varepsilon_{H}^{L}}-\gamma\left(\frac{\gamma w_{L}-w_{M}}{c}\right)$ depends negatively in the nonlinear way on the following variables: the high-skilled wage, the low-skilled 
wage, outsourcing wage and outsourcing cost and the productivity of the outsourced labor input relative to the domestic low-skilled labor input.

The optimal low-skilled wage (19a-b) also the case of the monopoly labor union is an implicit form in the presence of outsourcing, because the mark-up $A^{f}=\left(\frac{\eta_{L}^{f}-\eta_{H}^{f} \frac{\varepsilon_{L}^{H}}{\varepsilon_{H}^{H}} \frac{T}{U}}{\eta_{L}^{f}-\eta_{H}^{f} \frac{\varepsilon_{L}^{H}}{\varepsilon_{H}^{H}} \frac{T}{U}-1}\right)$ depends on the low-skilled wage rate in a non-linear way so that it cannot be solved explicitly for the optimal domestic low-skilled wage.

Equations (19a-b)) can be expressed as

$$
\begin{gathered}
\left.w_{L}^{*}\right|_{\delta \neq 1}=\left(\frac{\bar{\eta}_{L}^{f}}{\bar{\eta}_{L}^{f}-1}\right) \hat{b}_{L}=\left(\frac{\left(\varepsilon_{L}^{L}-\frac{\varepsilon_{H}^{L} \varepsilon_{L}^{H}}{\varepsilon_{H}^{H}} \frac{T}{U}\right)\left(L^{*}+\gamma M^{*}\right)+\gamma\left(M^{*}+\frac{w_{M}}{c}\right)}{\left(\varepsilon_{L}^{L}-\frac{\varepsilon_{H}^{L} \varepsilon_{L}^{H}}{\varepsilon_{H}^{H}} \frac{T}{U}\right)\left(L^{*}+\gamma M^{*}\right)+\gamma\left(M^{*}+\frac{w_{M}}{c}\right)-1}\right) \hat{b}_{L} \\
\left.w_{L}^{*}\right|_{\delta=1}=\left(\frac{\bar{\eta}_{L}^{f}}{\bar{\eta}_{L}^{f}-1}\right) \hat{b}_{L}=\left(\frac{\bar{\varepsilon}\left(L^{*}+\gamma M^{*}\right)+\gamma\left(M^{*}+\frac{w_{M}}{C}\right)}{\bar{\varepsilon}\left(L^{*}+\gamma M^{*}\right)+\gamma\left(M^{*}+\frac{w_{M}}{c}\right)-1}\right) \hat{b}_{L},
\end{gathered}
$$

where $\bar{\eta}_{L}^{f}=\left(\varepsilon_{L}^{L}-\frac{\varepsilon_{H}^{L} \varepsilon_{L}^{H}}{\varepsilon_{H}^{H}} \frac{T}{U}\right)\left(1+\gamma \frac{M^{*}}{L^{*}}\right)+\frac{\gamma}{L^{*}}\left(M^{*}+\frac{w_{M}}{c}\right)$ and in the presence of $\delta=1$ we have the following form for low-skilled wage $\left.\bar{\eta}_{L}^{f}\right|_{\delta=1}=\bar{\varepsilon}\left(1+\gamma \frac{M^{*}}{L^{*}}\right)+\frac{\gamma}{L^{*}}\left(M^{*}+\frac{w_{M}}{C}\right)$ and $\bar{\varepsilon}=\frac{1}{1-\rho(1-a)}>1$

\section{IV.2. Comparative Statics of Low-Skilled Wage Formation}

In order to characterize the effect of parameters on the unskilled monopoly trade wage formation it is applied the implicit differentiation. In terms of comparative statics of the outside option for unemployment benefit we have from the implicit wage formation (20a) the following result 


$$
\left(1-\frac{\left[\left(\bar{\eta}_{L}^{f}-1\right) \frac{\partial \bar{\eta}_{L}^{f}}{\partial w_{L}}-\bar{\eta}_{L}^{f} \frac{\partial \bar{\eta}_{L}^{f}}{\partial w_{L}}\right]}{\left(\bar{\eta}_{L}^{f}-1\right)^{2}} \hat{b}_{L}\right) d w_{L}^{*}=\left(\frac{\bar{\eta}_{L}^{f}}{\left.\bar{\eta}_{L}^{f}-1\right)}\right) d \hat{b}_{L}
$$

so that by using $\hat{b}_{L}=w_{L}^{*}\left(\bar{\eta}_{f}-1\right) / \bar{\eta}_{f}$ this can be expressed as

$$
\frac{d w_{L}^{*}}{d \hat{b}_{L}}=\left(\frac{\bar{\eta}_{L}^{f}}{\bar{\eta}_{L}^{f}-1+\frac{\partial \bar{\eta}_{L}^{f}}{\partial w_{L}} \frac{w_{L}}{\bar{\eta}_{L}^{f}}}\right)>0
$$

where $\frac{\partial \bar{\eta}_{L}^{f}}{\partial w_{L}}=\left(1+\varepsilon_{L}^{L}-\frac{\varepsilon_{H}^{L} \varepsilon_{L}^{H}}{\varepsilon_{H}^{H}} \frac{T}{U}\right) \frac{\gamma M^{*}}{L^{*}}\left(\frac{M_{w_{L}}^{*} w_{L}}{M^{*}}-\frac{L_{w_{L}}^{*} w_{L}}{L^{*}}\right)-\frac{\gamma w_{M}}{c w_{L}} \frac{L_{w_{L}}^{*} w_{L}}{L^{*}}>0 \quad$ and $\bar{\eta}_{f}>1$. According to (22) the effect of outside option on low-skilled wage formation is qualitatively the same with and without outsourcing because the mark-up in the presence of CES utility function is $\left.A\right|_{M=0, \delta \neq 1}=\left(\frac{\left(\varepsilon_{L}^{L}-\frac{\varepsilon_{H}^{L} \varepsilon_{L}^{H}}{\varepsilon_{H}^{H}} \frac{T}{U}\right)}{\left(\varepsilon_{L}^{L}-\frac{\varepsilon_{H}^{L} \varepsilon_{L}^{H}}{\varepsilon_{H}^{H}} \frac{T}{U}\right)-1}\right)$ so that $\left.\frac{d w_{L}^{*}}{d \hat{b}_{L}}\right|_{M=0, \delta \neq 1}=\left.A\right|_{M=0}>0$. In the presence of $\delta=1$ without outsourcing the mark-up is $\left.A\right|_{M=0, \delta=1}=\left(\frac{\bar{\varepsilon}}{\bar{\varepsilon}-1}\right)$ so that $\left.\frac{d w_{L}^{*}}{d \hat{b}_{L}}\right|_{M=0, \delta=1}=\left.A\right|_{M=0, \delta=1}>0.8$

Differentiating the implicit wage formation (20a) with respect to the lowskilled wage and the outsourcing wage gives

8 Of course, in the absence of outsourcing the mark-up between outside option and wage formation $\left.A\right|_{M=0}>\left.A\right|_{M>0}>1$ is higher than in the presence of outsourcing. 
$\left(1-\frac{\left[\left(\bar{\eta}_{L}^{f}-1\right) \frac{\partial \bar{\eta}_{L}^{f}}{\partial w_{L}}-\bar{\eta}_{L}^{f} \frac{\partial \bar{\eta}_{L}^{f}}{\partial w_{L}}\right]}{\left(\bar{\eta}_{L}^{f}-1\right)^{2}} \hat{b}_{L}\right) d w_{L}^{*}=\frac{\left[\left[\left(\bar{\eta}_{L}^{f}-1\right) \frac{\partial \bar{\eta}_{L}^{f}}{\partial w_{H}}-\bar{\eta}_{L}^{f} \frac{\partial \bar{\eta}_{L}^{f}}{\partial w_{H}}\right]\right]}{\left(\bar{\eta}_{L}^{f}-1\right)^{2}} \hat{b}_{L} d w_{H}$

which can be expressed by using $\hat{b}_{L}=w_{L}^{*}\left(\bar{\eta}_{f}-1\right) / \bar{\eta}_{f}$ as follows

$$
\frac{d w_{L}^{*}}{d w_{M}}=-\left(\frac{\frac{\partial \bar{\eta}_{L}^{f}}{\partial w_{H}} \frac{w_{L}}{\bar{\eta}_{L}^{f}}}{\bar{\eta}_{L}^{f}-1+\frac{\partial \bar{\eta}_{L}^{f}}{\partial w_{L}} \frac{w_{L}}{\bar{\eta}_{L}^{f}}}\right)>0
$$

where

$$
\begin{aligned}
& \frac{\partial \bar{\eta}_{L}^{f}}{\partial w_{M}}=\left(1+\varepsilon_{L}^{L}-\frac{\varepsilon_{H}^{L} \varepsilon_{L}^{H}}{\varepsilon_{H}^{H}} \frac{T}{U}\right) \gamma\left[\frac{L^{*} M_{w_{H}}^{*}-M^{*} L_{w_{H}}^{*}}{L^{* 2}}\right]+\frac{\gamma}{C}\left[\frac{L^{*}-w_{M} L_{w_{H}}^{*}}{L^{* 2}}\right]= \\
& \frac{\left(1+\varepsilon_{L}^{L}-\frac{\varepsilon_{H}^{L} \varepsilon_{L}^{H}}{\varepsilon_{H}^{H}} \frac{T}{U}\right) \gamma M^{*}}{w_{H} L^{*}}\left[\frac{M_{w_{H}}^{*} w_{H}}{M^{*}}-\frac{L_{w_{H}}^{*} w_{H}}{L^{*}}\right]+\frac{\gamma}{c L^{*}}\left[1-\frac{L_{w_{H}}^{*} w_{H}}{L^{*}}\right]= \\
& -\frac{\left(1+\varepsilon_{L}^{L}-\frac{\varepsilon_{H}^{L} \varepsilon_{L}^{H}}{\varepsilon_{H}^{H}} \frac{T}{U}\right) \gamma M^{*}}{w_{H} L^{*}}\left[\frac{1}{c M^{*}}\left(1+\gamma \frac{M^{*}}{L^{*}}\right)+\frac{\gamma}{c L^{*}}\left(1-\frac{\gamma w_{M}}{L^{*}}\right)\right]<0
\end{aligned}
$$

and $\frac{\partial \bar{\eta}_{L}^{f}}{\partial w_{L}}>0$. These results are qualitative similar in the case of $\delta=1$ when $\left(1+\varepsilon_{L}^{L}-\frac{\varepsilon_{H}^{L} \varepsilon_{L}^{H}}{\varepsilon_{H}^{H}} \frac{T}{U}\right)=1+\bar{\varepsilon}$.

Also the effects of higher outsourcing cost are qualitatively similar, i,e. $\frac{d w_{L}^{*}}{d c}=-\left(\frac{\frac{\partial \bar{\eta}_{L}^{f}}{\partial c} \frac{w_{L}}{\bar{\eta}_{L}^{f}}}{\bar{\eta}_{L}^{f}-1+\frac{\partial \bar{\eta}_{L}^{f}}{\partial w_{L}} \frac{w_{L}}{\bar{\eta}_{L}^{f}}}\right)>0$ as $\frac{\partial \bar{\eta}_{L}^{f}}{\partial c}<0$ (equation (7a)) and equation (15a) implies $\frac{d w_{H}^{*}}{d c}<0$

In terms of comparative statics of the unskilled wage tax and the tax exemption we have the following results 


$$
\begin{aligned}
& \frac{d w_{L}^{*}}{d t_{L}}=\left(\frac{\bar{\eta}_{L}^{f}}{\bar{\eta}_{L}^{f}-1+\frac{\partial \bar{\eta}_{L}^{f}}{\partial w_{L}} \frac{w_{L}}{\bar{\eta}_{L}^{f}}}\right) \frac{b_{L}-e_{L}}{\left(1-t_{L}\right)^{2}}>0 \text { as } b_{L}-e_{L}>0 \\
& \frac{d w_{L}^{*}}{d e_{L}}=-\left(\frac{\bar{\eta}_{L}^{f}}{\bar{\eta}_{L}^{f}-1+\frac{\partial \bar{\eta}_{L}^{f}}{\partial w_{L}} \frac{w_{L}}{\bar{\eta}_{L}^{f}}}\right) \frac{t_{L}}{\left(1-t_{L}\right)}<0
\end{aligned}
$$

According to (26a-26b) the effects of wage tax and tax exemption on low-skilled wage formation are qualitatively the same with and without outsourcing because $\left.\frac{d w_{L}^{*}}{d t_{L}}\right|_{M=0}=\frac{\bar{\varepsilon}}{(\bar{\varepsilon}-1)} \frac{b_{L}-e_{L}}{\left(1-t_{L}\right)^{2}}>0$ and $\left.\frac{d w_{L}^{*}}{d e_{L}}\right|_{M=0}=-\frac{\bar{\varepsilon}}{(\bar{\varepsilon}-1)} \frac{t_{L}}{\left(1-t_{L}\right)}<0$. This is because these parameters do not affect the mark-up of wage formation, but have an effect only via the outside mark-up. Of course, in the absence of outsourcing the mark-up between outside option and wage formation $A_{M=0}=\frac{\bar{\varepsilon}}{\bar{\varepsilon}-1}=\frac{1}{\rho(1-a)}>1$ is higher than in the presence of outsourcing. Moreover, the equations (26a-26b) imply jointly with equation (15a) that $\frac{d w_{H}}{d t_{L}}<0$, and $\frac{d w_{H}}{d e_{L}}>0$ so that the higher wage tax and the higher outside option of unskilled workers will decrease the wage for the skilled labor, while the higher tax exemption of low-skilled workers will increase the wage for the skilled labor.

We can now summarize these findings in terms of the low-skilled wage formation in the presence of flexible outsourcing as follows.

Proposition 3 In the presence of flexible outsourcing in the case of highskilled workers' CES utility function in competitive labor market equilibrium

(a) the higher outside option will increase the wage for the low-skilled labor and therefore decrease the wage for the high-skilled labor and 
these qualitative results are also qualitatively similar but higher in the absence of outsourcing, and

(b) the higher outsourcing wage and the higher outsourcing cost will increase the wage for the low-skilled labor because the wage elasticity of the low-skilled labor will decrease and these will decrease the wage for the high-skilled labor.

\section{Effects of Labor Tax Policy Under Imperfectly and Perfective Competitive Domestic Labor Markets}

Next it is analyzed the effect of labor wage tax progression on wage formation and employment by the low-skilled workers and the high-skilled workers in domestic labor.

\section{V.1. Effects of low-skilled wage tax progression on wage and employment}

I assume that the tax reform will keep the relative tax burden per low-skilled worker, $t_{L}\left(w_{L}-e_{L}\right)$, constant, which means

$$
t_{L}-\frac{t_{L} e_{L}}{w_{L}}=R
$$

The government can raise the degree of wage tax progression by increasing $t_{L}$ and $e_{L}$ and allowing change in $w_{L}$ under the condition $d R=0 .{ }^{9}$ Formally we have

$$
\left.\frac{d e_{L}}{d t_{L}}\right|_{d R=0,}=\frac{\left(w_{L}^{*}-e_{L}+\frac{t_{L} e_{L}}{w_{L}^{*}} \frac{\partial w_{L}^{*}}{\partial t_{L}}\right)}{\left(t_{L}-\frac{t_{L} e_{L}}{w_{L}^{*}} \frac{\partial w_{L}^{*}}{\partial e_{L}}\right)}>0 .
$$

A way to define tax progression is to look at the average tax progression ( $A R P$ ), which is given by the difference between the marginal tax rate $t_{L}$ and the average tax rate $R$, $A R P \equiv t_{L} R$. Tax system is progressive if $A R P$ is positive and the progression is increases if the difference increases. 
Concerning the low-skilled wage effect of this reform we have $d w_{L}^{*}=\frac{\partial w_{L}^{*}}{\partial t_{L}} d t_{L}+\frac{\partial w_{L}^{*}}{\partial e} d e_{L}$. Dividing by $d t_{L}$ and substituting the RHS of (28) for $d e / d t_{L}$ gives (see Appendix B)

$$
\left.\frac{d w_{L}^{*}}{d t_{L}}\right|_{d R=0}=\frac{\left[\frac{\partial w_{L}^{*}}{\partial t_{L}}+\frac{\left(w_{L}^{*}-e_{L}\right)}{t_{L}} \frac{\partial w_{L}^{*}}{\partial e_{L}}\right]}{\left[1-\frac{e_{L}}{w_{L}^{*}} \frac{\partial w_{L}^{*}}{\partial e_{L}}\right]}<0
$$

so that a higher degree of wage tax progression, keeping the relative tax burden per low-skilled worker constant, will decrease the low-skilled wage rate. In the absence of outsourcing the qualitative effect is similar, i.e. $\left.\frac{d w_{L}^{*}}{d t_{L}}\right|_{d R=0, d M=0}<0$, but it is quantitatively different (see Appendix B).

Finally, it is characterized the unskilled employment effect by raising tax progression keeping the relative tax burden per unskilled worker constant to increase $t_{L}$ and $e$ according to (28), so that we have the following employment effect $d L^{*}=\left[L_{w_{L}^{*}}^{*}+L_{w_{H}}^{*} \frac{\partial w_{H}}{\partial w_{L}^{*}}\right]\left[\frac{\partial w_{L}^{*}}{\partial t_{L}} d t_{L}+\frac{\partial w_{L}^{*}}{\partial e} d e_{L}\right]$. Dividing this by $d t_{L}$ and substituting the RHS of (28) for $d e / d t_{L}$ gives

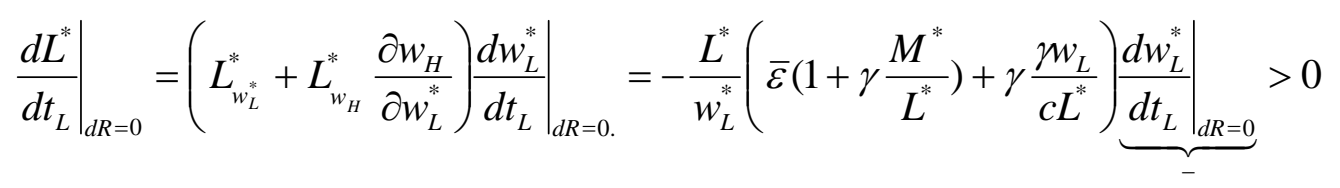

so that higher degree of wage tax progression keeping the relative tax burden per low-skilled worker constant, will increase the low-skilled labor demand. These results (29) and (30) also happen qualitatively in a similar way in the case of homogeneous domestic labor markets with outsourcing (see Koskela and Schöb (2010)). The qualitative effect is also similar in the absence of outsourcing because 
the higher degree of tax progression does not affect the mark-up of wage formation which depends on the presence and absence of outsourcing. ${ }^{10}$

The total effect concerning direct and indirect effects of changes in lowskilled wage on the skilled labor demand is in the case of CES utility function of high-skilled workers as follows

$$
\begin{aligned}
\left.\frac{d H^{*}}{d w_{L}^{*}}\right|_{\delta \neq 1} & =H_{w_{L}^{*}}^{H^{*}}+H_{w_{H}}^{*} \frac{d w_{H}}{d w_{L}^{*}}=\frac{H^{*}}{w_{L}^{*}}\left[-\varepsilon_{L}^{H}-\varepsilon_{H}^{H} \frac{\varepsilon_{L}^{H}}{\varepsilon_{H}^{H}} \frac{T}{U}\right]=\underbrace{-\frac{\varepsilon_{L}^{H}}{U} \frac{H^{*}}{w_{L}^{*}}}_{-}[U-T] \\
= & \underbrace{-\frac{\varepsilon_{L}^{H}}{U} \frac{H^{*}}{w_{L}^{*}}}_{-}\left(w_{H}\left(1-t_{H}\right)+t_{H} e_{L}\right)(\delta-1)\left\{\begin{array}{l}
< \\
= \\
>
\end{array}\right) \text { as } \quad \delta\left\{\begin{array}{l}
\delta \\
= \\
<
\end{array}\right)
\end{aligned}
$$

We can now summarize these findings in terms of the low-skilled wage formation and labor demand in the presence of flexible outsourcing as follows.

Proposition 4 In the presence of flexible outsourcing

(a) a higher degree of tax progression by raising the wage tax and the tax exemption for the low-skilled workers to keep the relative burden per low-skilled worker constant will decrease the wage rate and increase labor demand of low-skilled workers, whereas

(b) it will decrease (increase) employment of high-skilled workers in CES utility function when the elasticity of substitution between consumption and leisure is higher (lower) than one, while it will have no effect on employment of high-skilled workers in the case of the elasticity of substitution being one and

(c) qualitatively similar effects arise in the absence of outsourcing.

\section{V.2. Effects of high-skilled wage tax progression on wage and employment}

This has been analyzed in the absence of outsourcing under imperfectly competitive homogeneous domestic labor markets e.g. in Koskela and Vilmunen (1996) and in Koskela and Schöb (2002). 
I assume that the tax reform will keep the relative tax burden per high-skilled worker, $t_{H}\left(w_{H}-e\right)$, constant, which means

$$
t_{H}-\frac{t_{H} e_{H}}{w_{H}}=R^{H}
$$

The government can raise the degree of wage tax progression by increasing $t_{H}$ and $e_{H}$ and allowing change in $w_{H}$ under the condition $d R^{H}=0$. Formally we have

$$
\left.\frac{d e_{H}}{d t_{H}}\right|_{d R^{H}=0,}=\frac{\left(w_{H}^{*}-e_{H}+\frac{t_{H} e_{H}}{w_{H}^{*}} \frac{\partial w_{H}^{*}}{\partial t_{H}}\right)}{\left(t_{H}-\frac{t_{H} e_{H}}{w_{H}^{*}} \frac{\partial w_{H}^{*}}{\partial e_{H}}\right)}>0 .
$$

Concerning the high-skilled wage effect of this reform we have $d w_{H}^{*}=\frac{\partial w_{H}^{*}}{\partial t_{H}} d t_{H}+\frac{\partial w_{L}^{*}}{\partial e_{H}} d e_{H}$. Dividing by $d t_{H}$ and substituting the RHS of (33) for $d e_{H} / d t_{H}$ gives

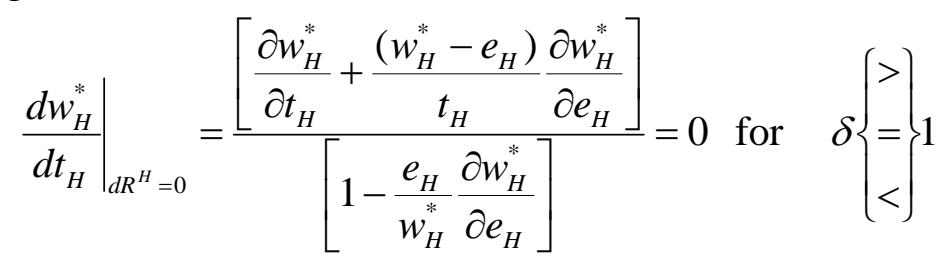

because the numerator is zero (see Appendix C) so that a higher degree of wage tax progression, keeping the relative tax burden per high-skilled worker constant, will have no effect on the high-skilled wage in the presence of CES utility function. Because there are no effect of high-skilled wage tax progression on high-skilled and low-skilled wage in the case of different tax parameters compared with low-skilled workers, there is no employment effects in this case.

We can now summarize these findings regarding the properties of the domestic labor demand in the presence of flexible outsourcing as follows.

Proposition 5 In the presence of flexible outsourcing

(a) a higher degree of wage tax progression for the high-skilled worker , keeping the relative tax burden per high-skilled worker constant, will 
have no effect on the high-skilled wage in the presence of CES utility function, and

(b) this higher-degree of tax progression will have no employment effect.

\section{V.3. Equilibrium Unemployment of Low-Skilled Workers}

It is now moved on to explore the determinants of equilibrium unemployment of unskilled workers in dual labor markets, when there is both unionized and competitive determination of wages in the home country. Consider a representative industry according to equation (19) the monopoly labor union sets the wages according to $w_{L}^{*}=\mathrm{A}^{f} \hat{b}_{L}$, for unskilled workers with the mark-up $\mathrm{A}^{f}$. Assume that all industries are identical and for that reason one can neglect industry-specific indices. In a general equilibrium context with labor mobility across identical industries, but no mobility across different labor market segments or professions, the endogenous outside option. By assuming that the taxation is linearly progressive both in the presence of getting employment in identical industries and in the case of not getting employment but unemployment benefit, which we specify as

$$
b_{L}=(1-u)\left(w_{L}\left(1-t_{L}\right)+t_{L} e_{L}\right)+u\left(B_{L}\left(1-t_{L}\right)+t_{L} e_{L}\right)
$$

where $u$ denotes the unemployment rate, $B_{L}$ denotes the unemployment benefit for workers of type $i$ and $w_{i}$ denotes the wage determined by the union for workers of type $i{ }^{11}$ In line with the literature we restrict ourselves to a benefit-replacement ratio $q \equiv B_{L} / w_{L}$, which is constant across the two labor market segments. Combining (19a) and (35) equation (35) can be expressed as

11 For a standard justification of this interpretation, see e.g. Nickell and Layard (1999) p. 30483049 for a further discussion. Nickell, S. and R. Layard (1999): Labor Market Institutions and Economic Performance, in Ashenfelter, O. and D. Card (eds): Handbook of Labor Economics, Volume 3C, 3029-3084. 


$$
\begin{aligned}
& b_{L}=(1-u)\left(w_{L}\left(1-t_{L}\right)+t_{L} e_{L}\right)+u\left(q w_{L}\left(1-t_{L}\right)+t_{L} e_{L}\right)= \\
& w_{L}\left(1-t_{L}\right)+t_{L} e_{L}+u(q-1) w_{L}\left(1-t_{L}\right)
\end{aligned}
$$

Under this assumption we have $\hat{b}_{L}=\frac{b_{L}-t_{L} e}{1-t_{L}}=w_{L}^{*}+u(q-1) w_{L}^{*}$ and $w_{L}^{*}=A^{f} \hat{b}_{L}$ can be written in terms of endogenous outside option as $w_{L}^{*}=A^{f}\left[w_{L}^{*}+u(q-1) w_{L}^{*}\right]$. In this case, the equilibrium unskilled unemployment can be presented as

$$
u=\frac{1}{(1-q)}\left(1-\frac{1}{A^{f}}\right)
$$

A higher benefit-replacement ratio $q$, which we assumed to be exogenous, will increase equilibrium unemployment. According to (28), in the presence of a constant benefit-replacement ratio $q=\bar{b}_{L} / w_{L}^{*}$, the impact of outsourcing on equilibrium unemployment comes via the mark-up $A^{f}=\frac{\bar{\varepsilon}\left(L^{*}+M\right)}{(\bar{\varepsilon}-1) L^{*}+\bar{\varepsilon} M}$.

According to (36) the equilibrium unemployment in each segment depends positively both on the benefit-replacement ratio $(q)$ and on the wage mark-up in the labor market. ${ }^{12}$ By substituting the wage mark-ups from (19a) into (36) one can explicitly characterize the equilibrium unemployment among the low-skilled workers, given outsourcing. As mentioned earlier the mark-up of unskilled wage formation $A^{f}$ in the presence of perfectly competitive skilled labor market is higher than in

12 The unemployment rate satisfies $0<u<1$ if and only if $q<\frac{1}{A^{f}}$, which it is assumed to hold throughout the analysis. In light of available data for 20 OECD countries Bassanini and Duval (2006) report the average benefit-replacement ratio to $(q)$ be approximately 0.27 with country observations in the interval $[0.13,0.65]$. The average benefit-replacement ratio in OECD countries has mainly increased from the 1960s (see e.g. Table 2 in Nickell et al. (2005)).See Bassanini, A. and R. Duval (2006): Employment Patterns in OECD Countries: Reassessing the Role of Policies and Institutions. OECD Economics Department Working Paper No. 486, 2006 and Nickell, S., Nunziata, L. and W. Ochel (2005): Unemployment in the OECD Since the 1990s. What Do We Know?, Economic Journal, 115, 1-27. 
the absence of the part of perfectly competitive labor market so that this heterogeneous labor market wage formation of the unskilled workers is higher than in the homogenous unskilled labor market. The monopoly union will increase the low-skilled wage and therefore it will decreases the skilled wage according to equation (15a) so that in the presence of of partly perfectly competitive domestic labor market, the equilibrium unemployment of low-skilled workers is higher, ceteris paribus.

$$
\text { In terms of outsourcing effect it gives } \frac{d u}{d M}=\frac{1}{(1-q)} \underbrace{\frac{d A^{f}}{A^{f^{2}}}}_{-}<0
$$

so that higher outsourcing will decrease the equilibrium unemployment of lowskilled workers because outsourcing will have a negative effect of wage formation. Differentiating equation (36) in terms of wage tax $t_{L}$ gives via $w_{L}^{*}$ and $M$

$$
\frac{d u}{d t_{L}}=\frac{1}{(1-q)} \underbrace{\frac{d A^{f}}{d t_{L}}}_{-} \underbrace{A^{f^{2}}}<0 \text { as } b_{L}>e_{L}
$$

so that the total effect of a higher wage tax on the wage of low-skilled workers is negative and thereby increases the wage elasticity and lowers the mark-up because of a lower labor demand. In terms of tax exemption $e_{L}$ for low-skilled workers we have

$$
\frac{d u_{L}}{d e_{L}}=\frac{1}{(1-q)} \frac{\frac{d A^{f}}{d e_{L}}}{\underbrace{A^{f^{2}}}_{+}}>0
$$

so that tax exemption in the presence of outsourcing will have a positive effect on equilibrium unemployment. This is because the total effect of a higher tax exemption on the wage of low-skilled workers is positive and, thereby, decreases the wage elasticity and raises the mark-up because of a higher labor demand and a decrease in outsourcing.

Now the analysis concentrates on the effects of tax progression for wage formation and employment by looking as the tax reform that increases tax progression while keeping the average tax burden per worker constant so that 
equation (27) $t_{L}-\frac{t_{L} e_{L}}{w_{L}}=R$ is constant. The average tax rate progression ( $A R P$ ) is given by the difference between the marginal tax rate $t_{L}$ and the average tax rate $t_{L}^{a}$, $A R P \equiv t_{L}-t_{L}^{a}$. The tax system is progressive if $A R P$ is positive and progression is increased if $A R P$ increases. Government raises the degree of tax progression by increasing $t_{L}$ and adjusts $e_{L}$ upwards such that $t_{L}^{a}$ remains constant. In this analysis the fully-balanced public sector budget aspect is not considered, because only some sectors may engage outsourcing, but not the whole economy.

First the analysis focuses the wage effect of this tax reform under Nash domestic wage bargaining. Differentiating (27) with respect to $t_{L}, e_{L}$ and $w_{L}$ to keep it constant gives $d e_{L}=\frac{\left(w_{L}-e_{L}\right)}{t_{L}} d t_{L}+\frac{e_{L}}{w_{L}} d w_{L}$ and the total wage effect is $d w_{L}=w_{L t_{L}} d t_{L}+w_{L e_{L}} d e_{L}$. Substituting the RHS of $d e_{L}=\frac{\left(w_{L}-e_{L}\right)}{t_{L}} d t_{L}+\frac{e_{L}}{w_{L}} d w_{L}$ for $d e_{L}$ in $d w_{L}=w_{L t_{L}} d t_{L}+w_{L e_{L}} d e_{L}$, where $w_{L t_{L}}=\frac{\partial w_{L}}{\partial t_{L}}$ and $w_{L e_{L}}=\frac{\partial w_{L}}{\partial e_{L}}$, gives

$$
\left.\frac{d w_{L}}{d t_{L}}\right|_{d R=0}=\frac{\left(w_{L t_{L}}+\frac{\left(w_{L}-e_{L}\right)}{t_{L}} w_{L e_{L}}\right)}{\left(1-\frac{w_{L e_{L}} e_{L}}{w_{L}}\right)}<0
$$

where

$$
\begin{aligned}
& \left(1-\frac{w_{L e_{L}} e_{L}}{w_{L}}\right)>0 \text { and }\left(w_{L t_{L}}+\frac{\left(w_{L}-e_{L}\right)}{t_{L}} w_{L e_{L}}\right)=-\frac{A^{f}}{\left(1-\frac{A_{w_{L}}^{f} w_{L}}{A^{f}}\right)} \frac{\left[w_{L}\left(1-t_{L}\right)+t_{L} e_{L}-b\right]}{\left(1-t_{L}\right)^{2}}<0 \\
& \text { so that }\left.\frac{d u_{L}}{d t_{L}}\right|_{d R=0}=\frac{1}{1-q} \frac{\left.\frac{d A^{f}}{d t_{L}}\right|_{d R=0}}{\left(A^{f}\right)^{2}}<0 .
\end{aligned}
$$

These findings can be summarized as 
Proposition 6 When the benefit-replacement ratio is fixed and less than one and unemployment benefits are taxed as unskilled wages, a higher wage tax rate and a lower tax exemption will decrease equilibrium unemployment in the presence of outsourcing and the average tax burden per worker constant so that $t_{L}-\frac{t_{L} e_{L}}{w_{L}}=R$ is constant and higher lowskilled tax progression will decrease unemployment.

\section{Conclusions}

Most western European countries are characterized by dual labor markets, in which wages of some workers are set by labor unions, while other wages are determined competitively. In this paper I have studied an economy in which unskilled workers form a monopoly labor union, while skilled workers are employed in competitive labour markets. I analyze how the presence of flexible outsourcing, which is decided after the unskilled wage is set by the monopoly labor union, affects such an economy.

It has been shown in the presence of flexible outsourcing both in the case of high-skilled workers' CES utility function and in the case of elasticity of substitution between consumption and leisure being one in competitive labor market equilibrium (a) the high-skilled wage depends negatively on the low-skilled wage, whereas (b) the high-skilled wage depends positively (negatively) on the wage tax when the elasticity of substitution between consumption and leisure is higher (lower) than one, whereas (c) the high-skilled wage depends negatively (positively) on the tax exemption when the elasticity of substitution between consumption and leisure is higher (lower) than one, while the high-skilled wage is independent of tax parameters under Cobb-Douglas utility function. Moreover both in the case of high- skilled workers' CES utility function and the elasticity of substitution between consumption and leisure is one in competitive labor market equilibrium higher outsourcing wage and higher outsourcing cost will increase the wage for the low-skilled labor because 
the wage elasticity of the low-skilled labor will decrease and they will decrease the wage for the high-skilled labor.

A higher low-skilled wage tax rate will increase the wage for the low-skilled labour and decrease the wage for high-skilled labour and the higher low-skilled wage tax exemption will decrease the wage for the low-skilled labor and will increase the wage for the high-skilled labor. Similar qualitative effects arise in the absence of outsourcing. In terms of labor tax reform (a) a higher degree of tax progression by raising the wage tax and the tax exemption for the low-skilled workers to keep the relative burden per low-skilled worker constant will decrease the wage rate and increase labor demand of low-skilled workers, whereas (b) it will decrease (increase) employment of high-skilled workers in CES utility function when the elasticity of substitution between consumption and leisure is higher (lower) than one, (c) while it will have no effect on employment of high-skilled workers in the case of CobbDouglas utility function of high-skilled workers.

Finally, it has been shown that a higher degree of wage tax progression for the high-skilled worker, keeping the relative tax burden per high-skilled worker constant, will have no effect on the high-skilled wage in the presence of CES utility function independent of the elasticity of substitution between consumption and leisure. Because there are no effect of high-skilled wage tax progression on highskilled and low-skilled wage in the case of different tax parameters compared with low-skilled workers, there is no employment effects in this case.

This framework suggests avenues for further research. I only focus on two new aspects. First, the resources that domestic firms spend on outsourcing will give rise to welfare effects in other countries. This suggests that uncoordinated policies might be inefficient from the perspective of society as a whole, and that outsourcing may provide an argument for policy coordination across countries. This has been studied by Aronsson and Sjögren (2004) in the absence of outsourcing. Second, it is also very useful to study what are the implications of optimal monetary policy under heterogeneous labor markets and outsourcing in the case of product market imperfections, whether due to monopolistic or oligopolistic competition. 


\section{Appendix A: Optimal Low-skilled Wage Setting under Linearly Progressive Wage Taxation}

The first-order condition associated with $\underbrace{\max }_{\left(w_{L}\right)} V=\left(\hat{w}_{L}-b_{L}\right) L$ s.t. $\pi_{L}=0$ and $H^{*}=H^{s}$ can be written as follows

$V_{w_{L}}=\frac{L^{*}}{w_{L}}\left[\left(1-t_{L}\right) w_{L}+\left(\left(1-t_{L}\right) w_{L}+t_{L} e_{L}-b_{L}\right)\left(\frac{L_{w_{L}}^{*} w_{L}}{L^{*}}+\frac{L_{w_{H}}^{*} w_{H}}{L^{*}} \frac{d w_{H}}{d w_{L}} \frac{w_{L}}{w_{H}}\right)\right]=0$

where the own wage elasticity of the low-skilled labor demand is $\eta_{L}^{f}=\varepsilon_{L}^{L}\left(1+\gamma \frac{M^{*}}{L^{*}}\right)+\frac{\gamma}{L^{*}}\left(M^{*}+\frac{w_{M}}{c^{*}}\right)$ and the cross wage elasticity is $\eta_{H}^{f}=\varepsilon_{H}^{L}\left(1+\gamma \frac{M^{*}}{L^{*}}\right) \quad$ and the low-skilled labor demand is $L^{*}=m w_{L}^{-\varepsilon_{L}^{L}} w_{H}^{-\varepsilon_{H}^{L}}-\gamma M^{*}=m w_{L}^{-\varepsilon_{L}^{L}} w_{H}^{-\varepsilon_{H}^{L}}-\gamma\left(\frac{\gamma w_{L}-w_{M}}{c}\right)$. Equation (A1) can be expressed as equation (19a) in the text.

$$
w_{L}^{*}=\left(\frac{\eta_{L}^{f}+\eta_{H}^{f} \frac{d w_{H} w_{L}}{d w_{L} w_{H}}}{\eta_{L}^{f}+\eta_{H}^{f} \frac{d w_{H} w_{L}}{d w_{L} w_{H}}-1}\right) \hat{b}_{L}
$$

In the case of the CES utility function we have

$w_{H}^{-\varepsilon_{H}^{H}}+\left(\frac{1-\alpha}{\alpha}\right)^{\delta} w_{H}^{1-\varepsilon_{H}^{H}-\delta}=\frac{(1-a)}{m a} w_{L}^{\varepsilon_{L}^{H}}$

so that

$\left.\frac{d w_{H}}{d w_{L}}\right|_{\delta \neq 1}=\frac{\varepsilon_{L}^{H} \frac{(1-a)}{m a} w_{L}^{\varepsilon_{L}^{H}-1}}{\left(-\varepsilon_{H}^{H} w_{H}^{-\varepsilon_{H}^{H}-1}+\left(\frac{1-\alpha}{\alpha}\right)^{\delta}\left[\left(1-t_{H}\right)\left(1-\varepsilon_{H}^{H}-\delta\right)-\varepsilon_{H}^{H} t_{H} e w_{H}^{-1}\right] w_{H}^{-\varepsilon_{H}^{H}} \hat{w}_{H}^{-\delta}\right)}<0$

where $1-\varepsilon_{H}^{H}-\delta<0$. Using (A3) and (A4) gives 


$$
\begin{aligned}
\left.\frac{d w_{H}}{d w_{L}} \frac{w_{L}}{w_{H}}\right|_{\delta \neq 1}= & \frac{\varepsilon_{L}^{H} \frac{(1-a)}{m a} w_{L}^{\varepsilon_{L}^{H}}}{\left(-\varepsilon_{H}^{H} w_{H}^{-\varepsilon_{H}^{H}}+\left(\frac{1-\alpha}{\alpha}\right)^{\delta}\left[w_{H}\left(1-t_{H}\right)\left(1-\varepsilon_{H}^{H}-\delta\right)-\varepsilon_{H}^{H} t_{H} e_{L}\right] w_{H}^{-\varepsilon_{H}^{H}} \hat{w}_{H}^{-\delta}\right)} \\
= & \frac{\varepsilon_{L}^{H} w_{H}^{-\varepsilon_{H}^{H}}\left[1+\left(\frac{1-\alpha}{\alpha}\right)^{\delta} \hat{w}_{H}^{1-\delta}\right]}{-\varepsilon_{H}^{H} w_{H}^{-\varepsilon_{H}^{H}}\left[1+\left(\frac{1-\alpha}{\alpha}\right)^{\delta} \hat{w}_{H}^{1-\delta}-\left(\frac{1-\alpha}{\alpha}\right)^{\delta} w_{H}(1-\delta) \hat{w}_{H}^{-\delta}\right]}=-\frac{\varepsilon_{L}^{H}}{\varepsilon_{H}^{H}} \frac{T}{U}<0 \\
\text { where } T= & 1+\left(\frac{1-\alpha}{\alpha}\right)^{\delta} \hat{w}_{H}^{1-\delta}>0 \text { and } U=1+\left(\frac{1-\alpha}{\alpha}\right)^{\delta} \hat{w}_{H}^{-\delta}\left(t_{H} e_{H}+w_{H}\left(1-t_{H}\right) \delta\right)>0 .
\end{aligned}
$$
Therefore, we have the low-skilled wage decided by the monopoly labor union in the presence of high-skilled workers' CES-utility functions

$$
\left.w_{L}^{*}\right|_{\delta \neq 1}=\left(\frac{\eta_{L}^{f}-\eta_{H}^{f} \frac{\varepsilon_{L}^{H}}{\varepsilon_{H}^{H}} \frac{T}{U}}{\eta_{L}^{f}-\eta_{H}^{f} \frac{\varepsilon_{L}^{H}}{\varepsilon_{H}^{H}} \frac{T}{U}-1}\right) \hat{b}_{L} \text { and }\left.w_{L}^{*}\right|_{\delta=1}=\left(\frac{\eta_{L}^{f}-\eta_{H}^{f} \frac{\varepsilon_{L}^{H}}{\varepsilon_{H}^{H}}}{\eta_{L}^{f}-\eta_{H}^{f} \frac{\varepsilon_{L}^{H}}{\varepsilon_{H}^{H}}-1}\right) \hat{b}_{L}
$$

where $\left.\frac{d w_{H}}{d w_{L}} \frac{w_{L}}{w_{H}}\right|_{\delta=1}=-\frac{\varepsilon_{L}^{H}}{\varepsilon_{H}^{H}}<0$. QED.

\section{Appendix B: Tax Progression and Low-skilled Labor Demand}

Substituting the RHS of (28) into $d w_{L}^{*}=\frac{\partial w_{L}^{*}}{\partial t_{L}} d t_{L}+\frac{\partial w_{L}^{*}}{\partial e} d e_{L}$ implies

$$
\left.\frac{d w_{L}^{*}}{d t_{L}}\right|_{d R=0}=\frac{\left(\frac{\partial w_{L}^{*}}{\partial t_{L}} t_{L}\left(1-\frac{e_{L}}{w_{L}^{*}} \frac{\partial w_{L}^{*}}{\partial e_{L}}\right)+\frac{\partial w_{L}^{*}}{\partial e}\left(w_{L}^{*}-e_{L}\right)+\frac{\partial w_{L}^{*}}{\partial e} \frac{t_{L} e_{L}}{w_{L}^{*}} \frac{\partial w_{L}^{*}}{\partial t_{L}}\right)}{t_{L}\left[1-\frac{e_{L}}{w_{L}^{*}} \frac{\partial w_{L}^{*}}{\partial e_{L}}\right]}
$$

which gives (29), where the denominator is positive. Concerning the numerator

$$
\begin{array}{r}
\frac{\partial w_{L}^{*}}{\partial t_{L}}+\frac{\left(w_{L}^{*}-e_{L}\right)}{t_{L}} \frac{\partial w_{L}^{*}}{\partial e_{L}} \text { in (29) we obtain that it is negative, i.e. } \\
\frac{\partial w_{L}^{*}}{\partial t_{L}}+\frac{\left(w_{L}^{*}-e_{L}\right)}{t_{L}} \frac{\partial w_{L}^{*}}{\partial e}=\frac{B}{\left(1-t_{L}\right)^{2}}\left(b_{L}-\hat{w}_{L}\right)<0
\end{array}
$$

where

$$
B=\frac{\bar{\eta}_{L}^{f}}{\bar{\eta}_{L}^{f}-1+\frac{\partial \bar{\eta}_{L}^{f}}{\partial w_{L}} \frac{w_{L}}{\bar{\eta}_{L}^{f}}}>0 \text { and } b_{L}-\hat{w}_{L}=b_{L}-\left(w_{L}^{*}\left(1-t_{L}\right)+t_{L} e_{L}\right)<0 \text {. }
$$

Without outsourcing we have the same qualitative, but quantitatively different result, i.e. 
$\left.\frac{d w_{L}^{*}}{d t_{L}}\right|_{d R=0, M=0}=\left[\frac{\partial w_{L}^{*}}{\partial t_{L}}+\frac{\left(w_{L}^{*}-e_{L}\right)}{t_{L}} \frac{\partial w_{L}^{*}}{\partial e}\right]_{M=0}=\frac{\bar{\varepsilon}}{(\bar{\varepsilon}-1)\left(1-t_{L}\right)^{2}}\left(b_{L}-\hat{w}_{L}\right)<0$.

QED.

\section{Appendix C: Tax Progression and High-skilled Labor Demand}

Using equations (15b-15c) and express the denominators as

$-\varepsilon_{H}^{H} w_{H}^{-\varepsilon_{H}^{H}-1}+\left(\frac{1-\alpha}{\alpha}\right)^{\delta}\left[\left(1-t_{H}\right)\left(1-\varepsilon_{H}^{H}-\delta\right)-\varepsilon_{H}^{H} t_{H} e_{H} w_{H}^{-1}\right] w_{H}^{-\varepsilon_{H}^{H}} \hat{w}_{H}^{-\delta}=X<0$,

we have

$\frac{\partial w_{H}^{*}}{\partial t_{H}}+\frac{\left(w_{H}^{*}-e_{H}\right)}{t_{H}} \frac{\partial w_{H}^{*}}{\partial e_{H}}=X^{-1}\left((1-\delta)\left(w_{H}-e_{H}\right)\left(\frac{1-\alpha}{\alpha}\right)^{\delta} w_{H}^{-\varepsilon_{H}^{H}} \hat{w}_{H}^{-\delta}\left(\frac{t_{H}-t_{H}}{t_{H}}\right)=0\right.$

QED.

\section{References:}

Aronsson, T. and T. Sjögren (2004): Efficient Taxation, Wage Bargaining and Policy Coordination, Journal of Public Economics, 88, 2711-2725.

Cahuc, P. and A. Zylberberg (2004): Labor Economics, the MIT Press.

Eckel, C. and H. Egger (2009): Wage Bargaining and Multinational Firms, Journal of International Economics, 77, 206-214.

Egger, H. and P. Egger (2006): International Outsourcing and the Productivity of Low-Skilled Labor in the EU, Economic Inquiry, 44, 98-108.

Ethier, W.J. (2005): Globalization, globalisation: Trade, Technology and Wages, International Review of Economics and Finance 14, 237-258.

Feenstra, R.C. and G.H. Hanson (1999): The Impact of Outsourcing and HighTechnology Capital on Wages: Estimates for the United States, 1979-1990, Quarterly Journal of Economics, 114, 907-940.

Geischecker, I. and H. Görg (2008): Winners and Losers: A Micro-Level Analysis of International Outsourcing and Wages, Canadian Journal of Economics, 41, 243-270.

Görg, H. and A. Hanley (2005): Labor Demand Effects of International Outsourcing: Evidence from Plant-Level Data, International Review of Economics and Finance, 14, 365-376. 
Hasan, R., D. Mitra and R.V. Ramaswamy (2007): Trade Reforms, Labor Regulations, and Labor-Demand Elasticities: Empirical Evidence from India, the Review of Economics and Statistics, 89(3), 466-481.

Hijzen, A. (2007): International Outsourcing, Technological Change, and Wage Inequality, Review of International Economics, 15, 188-205.

Hijzen, A., H. Görg and R.C. Hine (2005): International Outsourcing and the Skill Structure of Labor Demand in the United Kingdom, the Economic Journal, 115, 860-878.

Koskela, E. and R. Schöb (2002): Optimal Factor Income Taxation in the Presence of Unemployment, Journal of Public Economic Theory, 4, 387-404.

Koskela, E. and R. Schöb (2010): Outsourcing of Unionized Firms and the Impact of Labour Market Policy Reforms, Review of International Economics, 18(4), 682-695.

Koskela, E. and R. Stenbacka (2010): Equilibrium Unemployment with Outsourcing and Wage Solidarity under Labour Market Imperfections, European Economic Review, 54, 376-392.

Koskela, E. and J. Vilmunen (1996): Tax Progression is Good for Employment in Popular Models of Trade Union Behaviour, Labour Economics, 3, 65-80.

Lambert, P.J. (2001): The Distribution and Redistribution of Income, $3^{\text {rd }}$ edition, Manchester University Press.

Musgrave, R.A. and T. Thin (1948): Income Tax Progression, 1929-1948, Journal of Political Economy, 56, 498-514.

Riley, R. and G. Young (2007): Skill Heterogeneity and Equilibrium Unemployment, Oxford Economic Papers, 59, 702-725.

Sinn, H.-W. (2007): The Welfare State and the Forces of Globalization, CESifo Working Paper No. 1925.

Skaksen, J.R. (2004): International Outsourcing When Labor Markets are Unionized, Canadian Journal of Economics, 37(1), 78-94.

Slaughter, M.J. (2001): International Trade and Labor-Demand Elasticities, Journal of International Economics, 54, 27-56.

Stefanova, B.M. (2006): The Political Economy of Outsourcing in the European Union and the East-European Enlargement, Business and Politics 8, issue 2. 